\title{
A Meta-Analysis Based Modified Unified Theory of Acceptance and Use of Technology (Meta-UTAUT): A Review of Emerging Literature
}

\author{
Yogesh K. Dwivedi (Corresponding Author) \\ Emerging Markets Research Centre (EMaRC), School of Management, \\ Swansea University Bay Campus, Swansea, SA1 8EN, Wales, UK \\ Email: y.k.dwivedi@swansea.ac.uk
}

\author{
Nripendra P. Rana \\ International Business, Marketing and Branding Research Centre, School of Management, \\ University of Bradford, Bradford, UK \\ Email: nrananp@gmail.com
}

\author{
Kuttimani Tamilmani \\ International Business, Marketing and Branding Research Centre, School of Management, \\ University of Bradford, Bradford, UK \\ Email: kuttimani.tamilmani@gmail.com \\ Ramakrishnan Raman \\ Symbiosis Institute of Business Management, Pune \& Symbiosis International (Deemed) \\ University, Pune, India \\ Email: director@sibmpune.edu.in
}

\begin{abstract}
Over the last more than four decades, several theoretical models have been developed to understand the acceptance and use of information systems. Realising the dilemma in selecting the appropriate theoretical model to assess the acceptance and use of technology and considering the pattern of using the Unified Theory of Acceptance and Use of Technology (UTAUT), a modified version (metaUTAUT) has been developed based on the synthesis of results from 162 existing studies. The aim of this article is to review the emerging literature on meta-UTAUT and offer some future research recommendations. The analysis suggests that studies have started citing the relationships suggested by meta-UTAUT and researchers have reviewed it alongside other alternative models while analysing acceptance and use of technology.
\end{abstract}

Keywords: Adoption, Acceptance, Information Systems, Information Technology, Meta-UTAUT

\section{Introduction}

The acceptance and use of information systems (IS) and information technology (IT) has received extensive attention from researchers and practitioners in the last few decades [10, 25, 31, 47]. Several theoretical models have been proposed to understand the adoption of IS/IT including the theory of reasoned action (TRA), technology acceptance model (TAM), theory of planned behavior (TPB), unified theory of acceptance and use of technology (UTAUT) and extended UTAUT (i.e. UTAUT2) to name a few. These theories have used several different technological and contextual factors that influence the adoption of technologies in individual and organisational contexts.

Based on the extensive review and synthesis of alternative theoretical models, Venkatesh et al. [47] proposed UTAUT, which has become one of the most frequently used models of IS/IT adoption in current times $[9,10,50]$. UTAUT had included four moderators (i.e. age, gender, experience and voluntariness of use) to improve the predictive power of the model, which were not considered by preceding adoption theories. Since the evolution of UTAUT and its extension to UTAUT2, it has been utilised to examine adoption of various technologies in different contexts [50] including mobile health 
[11], mobile banking [4], m-wallet [16], mobile payment [42], mobile commerce [39], smart phone [5] and blockchain [30]. Based on these (and other such) studies it can be observed that although the UTAUT model explained considerable variance on intention and use behavior, such studies omitted examining certain relationships and testing the role of moderators. The model was also claimed to be complicated and was not used in its original form in several of the studies that utilised it.

Considering such issues, Dwivedi et al. [10] conducted a meta-analysis on results reported by 162 UTAUT-based empirical studies to modify the UTAUT model that we refer (hereafter) as the metaUTAUT model. In order to evaluate advances related to this modified meta-UTAUT model, the aim of this review article is to systematically review the emerging literature to assess the current state of employing meta-UTAUT for understanding individual adoption and use of IT/IS.

\section{Meta-analysis-based modified version of UTAUT (Meta-UTAUT)}

The meta-UTAUT model [10] has included four core exogenous variables (i.e. performance expectancy, effort expectancy, social influence and facilitating conditions) and two endogenous variables (i.e. behavioral intention and use behavior) of the original UTAUT [47]. Performance expectancy is the level to which an individual believes that an IS/IT system use will help them gain job performance whereas effort expectancy is the level of ease associated with the use of such system. Social influence is the degree to which an individual's important others believe that they should use the system whereas facilitating conditions are the measure of infrastructural support available for use of the system [47]. As per the meta-UTAUT model [10] (see Figure 1), performance expectancy, effort expectancy, social influence and facilitating conditions have both direct as well as indirect influence (via the attitudes construct) on behavioral intention to use IS/IT-based systems. The model also posits that the attitudes construct has both direct as well as indirect (via behavioral intention) effects on use behaviour. The model also demonstrates the role of facilitating conditions and intentions for directly predicting use behaviour. As outlined above and shown in Figure 1, meta-UTAUT has established the central role of attitudes as an additional mediating variable along behavioral intention between core exogenous variables (i.e. performance expectancy, effort expectancy, social influence and facilitating conditions) and ultimate dependent variable (i.e. use behavior) of the UTAUT model. Meta-UTAUT posited attitudes as an individual characteristic, which was not included in both UTAUT as well as the extended UTAUT (i.e. UTAUT2) model. The attitudes construct has been utilised along with different adoption models by previous studies [see for example, 9, 12], which suggests its appropriateness to be included as a core construct in IT/IS adoption models.

The model also provides the direct and mediating effect of attitudes onto use behavior, which implies that IS/IT-based innovation is used by individuals based on their attitudes towards technology in question even though they do not deliberately anticipate using such innovation. The significant departure of moderators from the meta-UTAUT model also makes it parsimonious and easier to use. As moderators may not be unanimously applicable in all different contexts, meta-UTAUT does not advocate a mandatory role of any moderating variable in this modified model.

\section{A review of citations of originating article of Meta-UTAUT}

A cited reference search for meta-UTAUT in Scopus resulted in 71 fully downloadable articles. The next phase involved classification of these articles through systematic review to uncover emerging use of meta-UTAUT theory across various technology use contexts. This resulted in classification of the citing articles into six broad categories as depicted in Table 1.

Conceptual model development and research design emerged as the largest category with 20 citations. A majority of the studies in this category operationalised constructs similar to meta-UTAUT and cited the theory to support the proposed casual relationships across a range of contexts including Jordanian consumers' behavioural intention towards mobile food ordering applications [1] and British students' cyberslacking behavioural intention [33]. In addition, studies in this category also adapted the research design employed in meta-UTAUT such as citation analysis [44] and meta-analysis and structural modelling (SEM) [6]. Literature review and theoretical background emerged as the second largest citation category comprising studies that cited meta-UTAUT in those sections. This involves drawing 
references to extant literature on how researchers have adopted/adapted a number of dominant technology adoption models including TAM, UTAUT and meta-UTAUT to identify factors that determine user intention to adopt new information technologies [2, 38].

The next category reference to the evolution of IS theories comprised 15 studies, which cited metaUTAUT in the introduction section. Researchers in this category acknowledged the necessity to reexamine popular models over time to accommodate evolving needs of technology users such as metaUTAUT that revised UTAUT through inclusion of attitudes as a mediator [8] and exclusion of UTAUT moderators [3]. Ten studies in the fourth category supporting findings with Meta-UTUAT cited the theory to support specific results that they obtained in their studies. This involves outcomes evolving from both construct/moderator relationships such as the mediating role of attitude in predicting intention and usage [14] and/or supporting reliability values of various constructs [27]. Four studies in the penultimate category acknowledged their limitation and how they can be addressed in the future using meta-UTAUT. Such studies recommended that inclusion of attitudes in the future may better explain variance of the research model to examine issues ranging from helpfulness of online reviews [26] to individual acceptance and use of mobile based IT solution [35]. The final category comprised three studies, which either utilised the theory as a whole [19] or in part by including external variables [20, 22].

Table 1. Meta-UTAUT general citation categories (Approach adapted from Tamilmani et al. [43])

\begin{tabular}{|c|c|c|c|}
\hline Citation category & Freq & Description & Example citations \\
\hline $\begin{array}{lr}\text { Conceptual } & \text { model } \\
\text { development } & \text { and } \\
\text { research design } & \end{array}$ & 20 & $\begin{array}{l}\text { Studies employing meta-UTAUT } \\
\text { casual relationships in their conceptual } \\
\text { model and adopting the elements of } \\
\text { meta-UTAUT research methodology }\end{array}$ & $\begin{array}{l}\text { Alalwan [1]; Chatterjee et al. [6] ; } \\
\text { Hossain et al. [21]; Kaffashi } \\
\text { and Shamsudin [23]; Kapoor } \\
\text { and Dwivedi [24]; Mehta et al. } \\
\text { [29]; Rana et al. [33] }\end{array}$ \\
\hline $\begin{array}{l}\text { Literature review and } \\
\text { Theoretical } \\
\text { background }\end{array}$ & 19 & $\begin{array}{l}\text { Reviewed meta-UTAUT study } \\
\text { alongside other dominant technology } \\
\text { adoption theories to fill the research gap }\end{array}$ & $\begin{array}{l}\text { Alam et al. [2]; Lithoxoidou et } \\
\text { al. [28]; Sharma et al. [38]; } \\
\text { Shiferaw and Mehari [40] }\end{array}$ \\
\hline $\begin{array}{llr}\begin{array}{l}\text { Reference } \\
\text { evolution } \\
\text { theories }\end{array} & \text { of } & \text { the } \\
\text { th }\end{array}$ & 15 & $\begin{array}{l}\text { Cited meta-UTAUT study while } \\
\text { discussing the evolution of technology } \\
\text { adoption theories }\end{array}$ & $\begin{array}{l}\text { Ameen and Willis [3]; Chatterjee } \\
\text { et al. [7]; Chea and Luo [8]; } \\
\text { Gaspar et al. [13]; Gursoy et al. } \\
\text { [17]; Shareef et al. [36, 37]; Tey } \\
\text { and Moses [45] }\end{array}$ \\
\hline $\begin{array}{l}\text { Supporting findings } \\
\text { with Meta-UTAUT }\end{array}$ & 10 & $\begin{array}{l}\text { Cited meta-UTAUT to support their } \\
\text { findings }\end{array}$ & $\begin{array}{l}\text { Gong et al. [14]; Gopalakrishna- } \\
\text { Remani et al. [15]; Heidt et al. } \\
\text { [18]; Hossain et al. [20]; Reading } \\
\text { et al. [34]; Veeramootoo et al. } \\
\text { [46] }\end{array}$ \\
\hline $\begin{array}{lr}\text { Limitations } & \text { and } \\
\text { Future } & \text { research } \\
\text { directions } & \\
\end{array}$ & 4 & $\begin{array}{l}\text { Cited meta-UTAUT while } \\
\text { acknowledging their limitation and how } \\
\text { they can be addressed in future }\end{array}$ & $\begin{array}{l}\text { Kaushik et al. [26]; Seethamraju } \\
\text { et al. [35]; Sinha et al. [41] }\end{array}$ \\
\hline $\begin{array}{l}\text { Meta-UTAUT } \\
\text { utilization }\end{array}$ & 3 & $\begin{array}{l}\text { Studied that employed meta-UTAUT as } \\
\text { a theoretical lens for their research } \\
\text { investigation }\end{array}$ & $\begin{array}{l}\text { Hoi [19]; Hossain et al. [20]; } \\
\text { Huseynov and Y1ldırım [22] }\end{array}$ \\
\hline
\end{tabular}

\section{Discussion}

The systematic review of meta-UTAUT citations reveals that the first two categories together represent $55 \%$ studies. This indicates meta-UTAUT is used to select constructs for their research model. Prior research suggests that while selecting constructs researchers should focus on including attributes specific to the context rather than having the urge to replicate the entire baseline model [48]. For instance, meta-UTAUT findings on underusage of moderators in the UTAUT model served as a basis for examining the role of a gender gap in smartphone adoption and use in Arab countries [3].

Meta-UTAUT has highlighted various such shortcomings of UTAUT and made significant contributions to theory through the re-examined model. Whetten [49] proposed a cross-context theorising framework to evaluate theory contributions from the contextulization perspective. Context 
effects can be broadly defined as the set of factors surrounding the focal phenomenon that exerts direct or indirect influence on it [49]. Three studies that utilised meta-UTAUT theory explicitly stated how the theory fits into the contextual setting commonly referred as contextualising theory (theories in context). Hoi [19] employed meta-UTAUT model without any modification in Vietnam - a developing country to examine mobile assisted language learning (MALL) among higher education learners. In addition, researchers have extended the meta-UTAUT model with additional constructs such as personal innovation and resistance to change to examine physicians adoption of electronic health records (EHR) in Bangladesh's healthcare system [20]. Meanwhile, Huseynov and Y1ldirım [22] extended the model with perceived enjoyment, compatiblity, perceived information security, and perceived social pressure in the Turkish context to examine consumers' shopping behaviours in B2C ecommerce platforms.

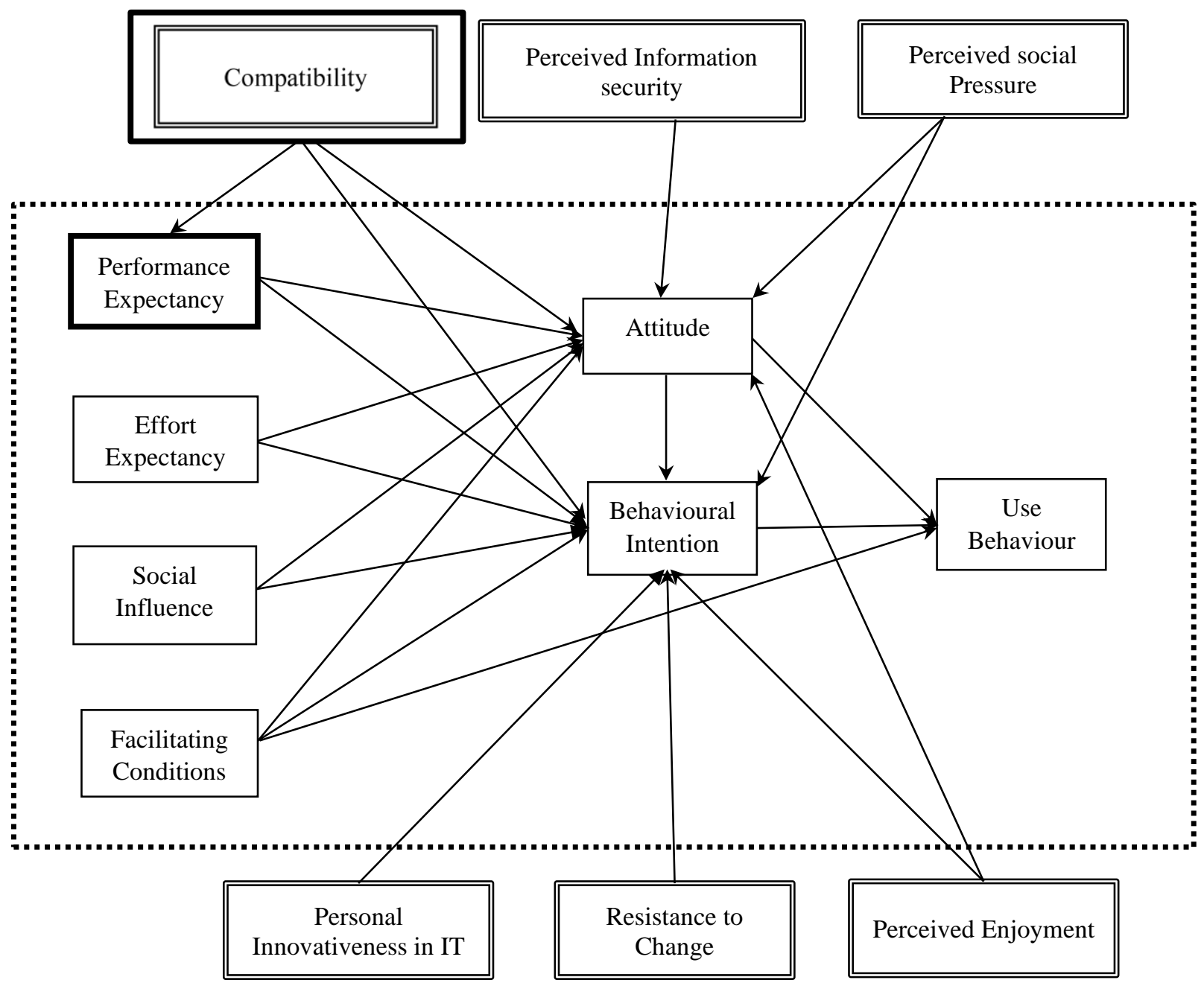

Figure 1. Meta-UTAUT extensions (Source: Adapted from Dwivedi et al. [10]; Hossain et al. [20]; Huseynov and Yildırım [22])

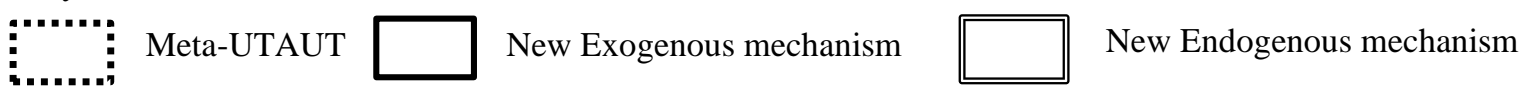

Venkatesh et al.'s [48] synthesis of UTAUT literature spanning across more than a decade found the UTAUT extensions category as a significant contributor of individual technology acceptance research. Along the similar lines, citation analysis of meta-UTAUT revealed two types of extension mechanisms and the emerging model is depicted in Figure 1. A new endogenous mechanism was the most popular meta-UTAUT extension, which refers to new associations between external variables and any of the three meta-UTAUT endogenous variables such as attitudes, intentions and usage. In addition, there was one exogenous mechanism, which refers to new associations between external variables and any of the 
four meta-UTAUT exogenous variables. Thus, meta-UTAUT has made contributions to theory by serving as a baseline model for guiding researchers to extend their conceptual model based on contextual conditions. In future, researchers should explore opportunities to extend meta-UTAUT through other mechanisms such a new outcome mechanisms that involve measuring consequences of technology use aside from behavioural intention and use behaviour [48].

\section{Conclusion}

This research paper performed a citation analysis and a brief review of articles that cited meta-UTAUT. The analysis suggests that the largest category of studies selected constructs similar to meta-UTAUT and cited the theory to support the proposed casual relationships. The second largest category comprised studies that cited meta-UTAUT in their literature review and theoretical background sections whereas the third largest category involved the studies where meta-UTAUT was cited while discussing the evolution of technology adoption models. The further use of meta-UTAUT was done where researchers used the reference of the paper on meta-UTAUT to support their findings. However, only a very limited number of studies have yet utilised meta-UTAUT as the underpinning theory for their proposed research model. The analysis presented in this article led to the conclusion that although the originating article of meta-UTAUT [10] has already gained sizable citations (more than 121 as per Scopus and 253 as per Google Scholar), it is yet to be widely utilized as a theoretical alternative for understanding adoption of emerging technologies.

\section{Conflict of interest statement - Nothing declared}

\section{References and recommended reading}

Papers of particular interest, published within the period of review, have been highlighted as:

* of special interest

** of outstanding interest

[1] Alalwan, A. A. (2020). Mobile food ordering apps: An empirical study of the factors affecting *customer e-satisfaction and continued intention to reuse. International Journal of Information Management, 50, 28-44. [This work utilised UTAUT2 factors to empirically predict the esatisfaction with Mobile food ordering apps and intention to reuse such apps in Jordan.]

[2] Alam, M. Z., Hoque, M. R., Hu, W., \& Barua, Z. (2020). Factors influencing the adoption of *mHealth services in a developing country: A patient-centric study. International Journal of Information Management, 50, 128-143. [This work utilised UTAUT factors to empirically predict intention to use mobile health services in Bangladesh. The study has also utilised Gender as a moderator]

[3] Ameen, N., \& Willis, R. (2018). An Analysis of the Moderating Effect of Age on Smartphone Adoption and Use in the United Arab Emirates. Paper presented at the Proceedings for the Conference on UK Academy of Information Systems (UKAIS). Available at: https://aisel.aisnet.org/ukais2018/1

[4] Baabdullah, A. M., Alalwan, A. A., Rana, N. P., Kizgin, H., \& Patil, P. (2019). Consumer use of *mobile banking (M-Banking) in Saudi Arabia: Towards an integrated model. International Journal of Information Management, 44, 38-52. [This work utilised UTAUT2 and IS success model to empirically predict intention to use mobile banking services in the Saudi Arabian context. This study examined both adoption and post adoption behaviour]

[5] Baishya, K., \& Samalia, H. V. (2020). Extending unified theory of acceptance and use of technology **with perceived monetary value for smartphone adoption at the bottom of the pyramid. International Journal of Information Management, 51 (April), $102036 . \quad$ DoI: https://doi.org/10.1016/j.ijinfomgt.2019.11.004 [This work integrated perceived monetary value with UTAUT to investigate the antecedents of smartphone adoption at the BOP in Indian context] 
[6] Chatterjee, S., Kar, A. K., \& Gupta, M. (2018). Success of IoT in smart cities of India: An empirical analysis. Government Information Quarterly, 35(3), 349-361.

[7] Chatterjee, S., Kar, A. K., Dwivedi, Y. K., \& Kizgin, H. (2019). Prevention of cybercrimes in smart cities of India: from a citizen's perspective. Information Technology \& People, 32(5), 1153-1183

[8] Chea, S., \& Luo, M. M. (2019). Pleasantness, Activation, and Negative Affectivity: A Test of Extended UTAUT Model. Paper presented at the Proceedings of the 52nd Hawaii International Conference on System Sciences. Available at http://hdl.handle.net/10125/59950

[9] Dwivedi, Y. K., Rana, N. P., Janssen, M., Lal, B., Williams, M. D., \& Clement, M. (2017). An **empirical validation of a unified model of electronic government adoption (UMEGA). Government Information Quarterly, 34(2), 211-230. [This work developed and validated a moderator-less UTAUT model that also included risk as an external factors for examining eGovernment adoption]

[10] Dwivedi, Y. K., Rana, N. P., Jeyaraj, A., Clement, M., \& Williams, M. D. (2019). Re-examining **the unified theory of acceptance and use of technology (UTAUT): Towards a revised theoretical model. Information Systems Frontiers, 21(3), 719-734. [This work developed a meta-analysis based and moderator-less UTAUT model, which is termed as meta-UTAUT in this review aricle.]

[11] Dwivedi, Y. K., Shareef, M. A., Simintiras, A. C., Lal, B., \& Weerakkody, V. (2016). A generalised *adoption model for services: A cross-country comparison of mobile health (m-health). Government Information Quarterly, 33(1), 174-187. [This work developed and validated a moderator-less UTAUT2 model that also included external factors for examining mHealth adoption]

[12] Dwivedi, Y., Khan, N., \& Papazafeiropoulou, A. (2006). Consumer adoption and usage of broadband in Bangladesh. AMCIS 2006 Proceedings, 426, Available at http://aisel.aisnet.org/amcis2006/426

[13] Gaspar, H., Morgado, L., Mamede, H., Oliveira, T., Manjón, B., \& Gütl, C. (2019). Research priorities in immersive learning technology: the perspectives of the iLRN community. Virtual Reality, $1-23$.

[14] Gong, X., Lee, M. K., Liu, Z., \& Zheng, X. (2018). Examining the role of tie strength in users' continuance intention of second-generation mobile instant messaging services. Information Systems Frontiers, 1-22. doi: https://doi.org/10.1007/s10796-018-9852-9

[15] Gopalakrishna-Remani, V., Jones, R. P., \& Camp, K. M. (2019). Levels of EMR adoption in US hospitals: An empirical examination of absorptive capacity, institutional pressures, top management beliefs, and participation. Information Systems Frontiers, 21(6), 1325-1344.

[16] Gupta, A., Yousaf, A., \& Mishra, A. (2020). How pre-adoption expectancies shape post-adoption continuance intentions: An extended expectation-confirmation model. International Journal of Information Management, 102094. doi: https://doi.org/10.1016/j.ijinfomgt.2020.102094

[17] Gursoy, D., Chi, O. H., Lu, L., \& Nunkoo, R. (2019). Consumers acceptance of artificially intelligent (AI) device use in service delivery. International Journal of Information Management, 49, 157-169.

[18] Heidt, M., Gerlach, J. P., \& Buxmann, P. (2019). Investigating the security divide between SME and large companies: How SME characteristics influence organizational IT security investments. Information Systems Frontiers, 21(6), 1285-1305.

[19] Hoi, V. N. (2020). Understanding higher education learners' acceptance and use of mobile devices for language learning: A Rasch-based path modeling approach. Computers \& Education, 146, 1-15.

[20] Hossain, A., Quaresma, R., \& Rahman, H. (2019). Investigating factors influencing the physicians' **adoption of electronic health record (EHR) in healthcare system of Bangladesh: An empirical study. International Journal of Information Management, 44, 76-87. [This work utilised meta-UTAUT factors (along with innovativeness and resistance to change as external factors) to empirically predict intention to use mobile health services.] 
[21] Hossain, M. A., Dwivedi, Y. K., Chan, C., Standing, C., \& Olanrewaju, A. S. (2018). Sharing political content in online social media: A planned and unplanned behaviour approach. Information Systems Frontiers, 20(3), 485-501.

[22] Huseynov, F., \& Özkan Yıldırım, S. (2019). Online consumer typologies and their shopping **behaviors in B2C e-commerce platforms. SAGE Open, 9(2), 9. [This work utilised a model similar to meta-UTAUT (along with several external factors) for empirically predicting online shopping behaviour]

[23] Kaffashi, S., \& Shamsudin, M. N. (2019). Transforming to a low carbon society; an extended theory of planned behaviour of Malaysian citizens. Journal of Cleaner Production, 235, 1255-1264.

[24] Kapoor, K. K., \& Dwivedi, Y. K. (2020). Sustainable consumption from the consumer's perspective: Antecedents of solar innovation adoption. Resources, Conservation and Recycling, 152, 104501.

[25] Kapoor, K. K., Dwivedi, Y. K., \& Williams, M. D. (2014). Innovation adoption attributes: a review and synthesis of research findings. European Journal of Innovation Management, 17(3), 327-348.

[26] Kaushik, K., Mishra, R., Rana, N. P., \& Dwivedi, Y. K. (2018). Exploring reviews and review sequences on e-commerce platform: A study of helpful reviews on Amazon.in. Journal of Retailing and Consumer Services, 45, 21-32.

[27] Leong, L.-Y., Hew, T.-S., Ooi, K.-B., Lee, V.-H., \& Hew, J.-J. (2019). A hybrid SEM-neural network analysis of social media addiction. Expert Systems with Applications, 133, 296-316.

[28] Lithoxoidou, E., Doumpoulakis, S., Tsakiris, A., Ziogou, C., Krinidis, S., Paliokas, I., ... \& Tzovaras, D. (2020). A novel social gamified collaboration platform enriched with shop-floor data and feedback for the improvement of the productivity, safety and engagement in factories. Computers \& Industrial Engineering, 139, 105691.

[29] Mehta, A., Morris, N. P., Swinnerton, B., \& Homer, M. (2019). The Influence of Values on Elearning Adoption. Computers \& Education, 141, 103617.

[30] Queiroz, M. M., \& Wamba, S. F. (2019). Blockchain adoption challenges in supply chain: An empirical investigation of the main drivers in India and the USA. International Journal of Information Management, 46, 70-82.

[31] Rana, N. P., Dwivedi, Y. K., \& Williams, M. D. (2013). Evaluating alternative theoretical models for examining citizen centric adoption of e-government. Transforming Government: People, Process and Policy, 7(1), 27-49.

[32] Rana, N. P., Dwivedi, Y. K., Lal, B., Williams, M. D., \& Clement, M. (2017). Citizens' adoption **of an electronic government system: towards a unified view. Information Systems Frontiers, 19(3), 549-568. [This work developed and validated a moderator-less UTAUT model that also included Anxity and Attitude as external factors for examining eGovernment adoption]

[33] Rana, N. P., Slade, E., Kitching, S., \& Dwivedi, Y. K. (2019). The IT way of loafing in class: Extending the theory of planned behavior (TPB) to understand students' cyberslacking intentions. Computers in Human Behavior, 101, 114-123.

[34] Reading, M., Baik, D., Beauchemin, M., Hickey, K. T., \& Merrill, J. A. (2018). Factors influencing sustained engagement with ECG self-monitoring: perspectives from patients and health care providers. Applied Clinical Informatics, 9(04), 772-781.

[35] Seethamraju, R., Diatha, K. S., \& Garg, S. (2018). Intention to use a mobile-based information technology solution for tuberculosis treatment monitoring-applying a UTAUT model. Information Systems Frontiers, 20(1), 163-181.

[36] Shareef, M. A., Baabdullah, A., Dutta, S., Kumar, V., \& Dwivedi, Y. K. (2018a). Consumer adoption of mobile banking services: An empirical examination of factors according to adoption stages. Journal of Retailing and Consumer Services, 43, 54-67. 
[37] Shareef, M. A., Mukerji, B., Alryalat, M. A. A., Wright, A., \& Dwivedi, Y. K. (2018b). Advertisements on Facebook: Identifying the persuasive elements in the development of positive attitudes in consumers. Journal of Retailing and Consumer Services, 43, 258-268.

[38] Sharma, S. K., Mangla, S. K., Luthra, S., \& Al-Salti, Z. (2018). Mobile wallet inhibitors: Developing a comprehensive theory using an integrated model. Journal of Retailing and Consumer Services, 45, 52-63.

[39] Shaw, N., \& Sergueeva, K. (2019). The non-monetary benefits of mobile commerce: Extending UTAUT2 with perceived value. International Journal of Information Management, 45, 44-55.

[40] Shiferaw, K. B., \& Mehari, E. A. (2019). Modeling predictors of acceptance and use of electronic medical record system in a resource limited setting: using modified UTAUT model. Informatics in Medicine Unlocked, 17, 100182.

[41] Sinha, A., Kumar, P., Rana, N. P., Islam, R., \& Dwivedi, Y. K. (2019). Impact of internet of things (IoT) in disaster management: a task-technology fit perspective. Annals of Operations Research, 283(12), 759-794.

[42] Slade, E. L., Williams, M. D., \& Dwivedi, Y. K. (2014). Devising a research model to examine adoption of mobile payments: An extension of UTAUT2. The Marketing Review, 14(3), 310-335.

[43] Tamilmani, K., Rana, N. P., \& Dwivedi, Y. K. (2017). A systematic review of citations of UTAUT2 article and its usage trends. Paper presented at the Conference on e-Business, e-Services and e-Society. Available at https://doi.org/10.1007/978-3-319-68557-1_5

[44] Tamilmani, K., Rana, N. P., Prakasam, N., \& Dwivedi, Y. K. (2019). The battle of Brain vs. Heart: A literature review and meta-analysis of "hedonic motivation" use in UTAUT2. International Journal of Information Management, 46, 222-235.

[45] Tey, T. C. Y., \& Moses, P. (2018). UTAUT: Integrating achievement goals and learning styles for undergraduates' behavioural intention to use technology. EAI Endorsed Transactions on e-Learning, 5(17), 1-12. DoI: http://dx.doi.org/10.4108/eai.25-9-2018.155573

[46] Veeramootoo, N., Nunkoo, R., \& Dwivedi, Y. K. (2018). What determines success of an egovernment service? Validation of an integrative model of e-filing continuance usage. Government information quarterly, 35(2), 161-174

[47] Venkatesh, V., Morris, M. G., Davis, G. B., \& Davis, F. D. (2003). User acceptance of information **technology: Toward a unified view. MIS Quarterly, 27(3), 425-478. [This article proposed and validated the widely used UTAUT theory]

[48] Venkatesh, V., Thong, J. Y., \& Xu, X. (2016). Unified Theory of Acceptance and Use of **Technology: A Synthesis and the Road Ahead. Journal of the Association for Information Systems, 17(5), 328-376. [This article has presented a comprehensive review of the UTAUT model].

[49] Whetten, D. A. (2009). An examination of the interface between context and theory applied to the study of Chinese organizations. Management and Organization Review, 5(1), 29-56.

[50] Williams, M. D., Rana, N. P., \& Dwivedi, Y. K. (2015). The unified theory of acceptance and use **of technology (UTAUT): a literature review. Journal of Enterprise Information Management, 28(3), 443. [This article has presented a comprehensive review of the UTAUT model]. 